\section{AL-AZHAR Dental Journal}

F o r

$\mathrm{G} \quad \mathrm{i} \quad \mathrm{r}$
The Official Publication of The Faculty of Dental

Medicine For Girls,

Al-Azhar University Cairo, Egypt.

\title{
Clinical and Radiographic Evaluation of Piezocision Corticotomy with Bone Graft Guided By 3D-Surgical Template in Maxillary Protrusion (comparative study)
}

\author{
Omneya E. Ahmed ${ }^{1 *}$, Naglaa S. El Kilani ${ }^{2}$, Samir A Ibrahim ${ }^{3}$, Ahmed E. Salama ${ }^{3}$ and Ghada A. Khalifa ${ }^{4}$
}

Codex : 56/20.07
azhardentj@azhar.edu.eg
http://adjg.journals.ekb.eg

DOI: $10.21608 /$ adjg.2020.18874.1201

Pediatric Dentistry \& Orthodontics ( Pediatric Dentistry, Orthodontics)

\section{KEYWORDS}

Piezocision, Minimally Invasive

Flapless Technique,

Augmented Corticotomy,

Platelet-Rich Fibrin.

\begin{abstract}
Purpose: The intent of the study was to compare the periodontal and bony changes of piezocision corticotomy with bone graft guided by 3D-surgical template in maxillary protrusion versus non grafted one. Patients and Methods: Prospective study included 20 maxillary protrusive female patients with age group ranging between 20 and 50 years. Patients were divided in to group I: treated with piezocision corticotomy without bone graft guided by 3D surgical template. Group II: treated with piezocision corticotomy with bone graft guided by 3D surgical template. CBCT scan was performed of all the patients. Gingival index (GI), probing depth (PD) and CBCT images were performed at baseline and 6months then collected data were analyzed using SPSS statistical analysis program. Results: There were significant reductions in GI, and PD of Group I and Group II from baseline to 3 months. Radiographic analysis of group II showed a statistically significant increase of labial bone thickness (LBT) after 6 months. Conclusion: The uses of guided bone regeneration during cortioctomy improve the clinical parameter and augment the labial bone with minimal loss of bone thickness during en-mass movement.
\end{abstract}

\section{INTRODUCTION}

Adult patients seeking orthodontic treatment have special biological conditions unlike children; there are collagen transition, quit cell mobilization and, raising the risk of periodontal disease. Such limitation

1. Assistant Lecturer of Oral Medicine, Periodontology, Oral Diagnosis and Radiology Department Faculty of Dental Medicine for Girls, Al-Azhar University, Cairo, Egypt.

2. Professor of Oral Medicine, Periodontology, Oral Diagnosis and Radiology Faculty of Dental Medicine for Girls, Al-Azhar University, Cairo, Egypt.

3. Professor of Orthodontic Department Faculty of Dental Medicine for Girls, Al-Azhar University, Cairo, Egypt.

4. Professor of maxillofacial surgery Department Faculty of Dental Medicine for Girls, Al-Azhar University, Cairo, Egypt.

* Corresponding author email: omneyaemam139@gmail.com 
prevents acceleration of treatment via conventional mean without exaggerating risk of hyalinization ${ }^{(1)}$.

The researchers have investigated several techniques that mingled with orthodontic treatment to speeding up tooth movement. These techniques may be surgical and non-surgical (2). Several surgical techniques were used in order to accelerate tooth movement are Corticotomy and Piezocision technique. Alveolar bone remodeling and periodontal ligament (PDL) are important factors in tooth movement and bone turnover was increased after bone grafting, fracture, and osteotomy ${ }^{(3)}$.

The concept of orthodontic acceleration came after establishment of Regional Acceleratory Phenomena (RAP) by Frost. RAP is a local response to noxious stimulus that causing $2-10$ times faster tissue regeneration than normal by elevating the different healing steps ${ }^{(4)}$. PAOO is a clinical technique that included corticotomy, bone grafting and orthodontic forces to preserve and increase the thickness of the cortical bone ${ }^{(5)}$.

In spite of the effectiveness of conventional corticotomy in decreasing orthodontic time, it has several disadvantages; its aggressive nature due to it requires full flaps elevation, wide removal of cortical bone and hematoma making this technique unaccepted moreover ${ }^{(6)}$. To overcome these drawbacks, minimally invasive techniques have been introduced. These procedures do not need flap rising and they use micro instruments to decrease tissue trauma. Some of these minimally invasive are piezocision, computer-guided piezocision ${ }^{(7,8)}$.

Like the tissue healing, RAP needs mixed of progenitor cells and signaling molecules in order to succeed ${ }^{(9)}$. This study is designated to evaluate the periodontal and bony changes of piezocision corticotomy with bone graft guided by 3D-surgical template in maxillary protrusion versus non grafted one clinically and radiographically using cone beam computer tomography (CBCT).

\section{PATIENTS AND METHODS}

Twenty maxillary protrusive female patients aged (18-25 years) were included in current study. The patients were seeking orthodontic treatment that entailing the extraction of maxillary first premolar teeth. Patients free from any systemic disease. Females with any signs of active periodontal disease or that undergone to previous periodontal surgeries were excluded.

Patients were divided into group I: treated with piezocision corticotomy without bone graft guided by 3D surgical template. (Control group). Group II: treated with piezocision corticotomy with bone graft guided by 3D surgical template. After patient selection, initial periodontal therapy and routine records of all the patients such pre-treatment study models, extra oral and intra oral photographs, lateral cephalograms, panoramic radiograph, have been done pre operatively for every patient.

Pre surgical orthodontic treatment phase that include leveling and alignment stage of orthodontics treatment plane, then construction of surgical guide was started immediately. Ultrasonic Piezotome using SG4 tip, is then used to perform corticotomy cuts through the gingival micro-incisions under copious saline irrigation.

After completion of the corticotomy procedure, a bovine xenograft with particle size (400-800 micron) was mixed with plasma in a sterile Dappen dish until a sandy consistency was obtained. PRF membrane was strickled underneath the mucosa and then the procedure was completed by suturing. Evaluation was done clinical and radiographiclly. Radiographic assessment was done using CBCT using Romix viewer. These measurements were performed at baseline and 6 months.

\section{Radiographic measurment}

In the sagital view, a line was drawn at CEJ's of the buccal surface. Then the labial alveolar bone thicknesses for maxillary incisors were measured at 3,6 and $9 \mathrm{~mm}$ distance represent cervical, mid root and apical points respectively by a single examiner ${ }^{(10)}$ Figure (1). 


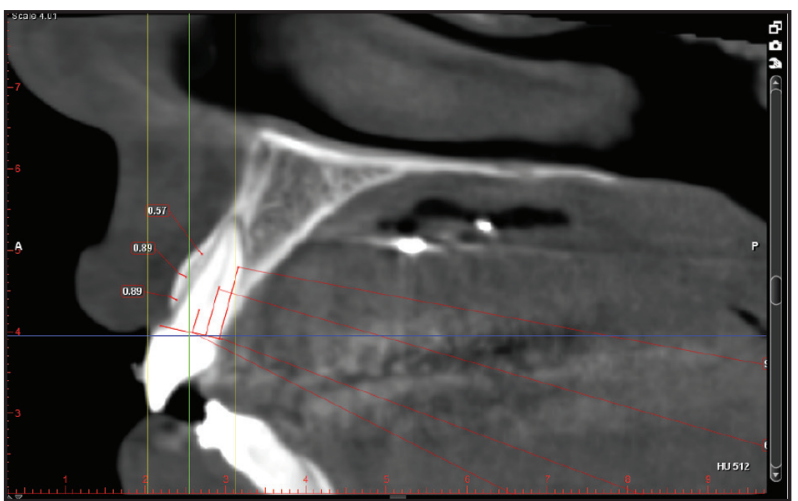

Figure (1): Sagittal section of CBCT image showing measurements of LBT.

\section{RESULTS}

\section{Clinical parameters}

From baseline to 6 months, there was no statistically significant change in mean GI in group I. while, group II showed a statistically significant decrease in mean GI. While both groups showed a statistically significant decrease in mean PD (table1).

Table (1): Comparison of means and SD for PD and GI within groups

\begin{tabular}{|c|c|c|c|c|c|c|c|c|c|c|}
\hline & \multicolumn{2}{|c|}{$\begin{array}{c}\text { Gr. I } \\
\text { (Base line) }\end{array}$} & \multicolumn{2}{|c|}{$\begin{array}{l}\text { Gr. I } \\
(6 \mathrm{~m})\end{array}$} & \multirow{2}{*}{$P$-value } & \multicolumn{2}{|c|}{$\begin{array}{c}\text { Gr. II } \\
\text { (Base line }\end{array}$} & \multicolumn{2}{|c|}{$\begin{array}{l}\text { Gr. II } \\
(6 \mathrm{~m})\end{array}$} & \multirow{2}{*}{$P$-value } \\
\hline \multirow{2}{*}{ PD } & Mean & SD & Mean & SD & & Mean & SD & Mean & SD & \\
\hline & 2.5 & 1 & 1.7 & 0.92 & $0.015^{*}$ & 2.9 & 0.98 & 2 & 0.32 & $0.015^{*}$ \\
\hline GI & 0.3 & 0.81 & 0.25 & 0.78 & 0.726 & 0.3 & 0.57 & 0.16 & 0.40 & $0.010^{*}$ \\
\hline
\end{tabular}

*: Significant at $P \leq 0.05$

\section{Radiographic analysis:}

At the end of the study, within control group, at cervical and midpoints there were no statistically significant increase in LBL. However, at the apical point, there was a significant decrease in LBL after 6 months. While in grafted group, there was significant increase in LB at 3 levels (table2).

Table (2): Comparison of means and SD for LBT within group:

\begin{tabular}{|c|c|c|c|c|c|c|}
\hline \multicolumn{2}{|c|}{} & \multicolumn{2}{|c|}{ Base line } & \multicolumn{2}{c|}{ 6month } & P-value \\
\cline { 3 - 7 } & Mean & SD & Mean & SD & \\
\hline \multirow{4}{*}{ Group I } & cervical & 1 & 0.22 & 0.8 & 0.3 & 0.726 \\
\cline { 2 - 7 } & Mid & 0.9 & 0.27 & 0.8 & 0.3 & 0.343 \\
\cline { 2 - 7 } & Apical & 0.9 & 0.29 & 0.6 & 0.3 & $0.016^{*}$ \\
\hline \multirow{4}{*}{ Group II } & cervical & 1 & 0.20 & 1.52 & 0.46 & $<0.001^{*}$ \\
\cline { 2 - 7 } & Mid & 1.04 & 0.18 & 1.6 & 0.27 & $<0.001^{*}$ \\
\cline { 2 - 7 } & Apical & 0.8 & 0.27 & 1 & 0.3 & 0.513 \\
\hline
\end{tabular}

*: Significant at $P \leq 0.05$

\section{DISCUSSION}

Minimally invasive corticotomies techniques have been newely introduced to overcome the drawbackes of conventional one. Moreover, the probability of restoring bone thickness and peridontium in one step technique made these approaches further respective ${ }^{(7)}$. Piezoelectric bone decortication was combined with selective tunneling that allowed for hard- or soft-tissue grafting. This novel approach led to a shorter treatment time, minimized discomfort, and greater patient acceptance ${ }^{(11)}$.

Concerning the results of current study, Group I and II have shown postoperative significant improvement of PD from baseline to 6 months and this clinical improvement could be attributed to non surgical periodontal therapy that reduces the 
number of periodontal pathogens in pockets causing inhibition of inflammatory process ${ }^{(12)}$.

This in accordance with previous study that stated the reason for the absence of any adverse effects on the periodontium after corticotomy could be the manner of bone removal as the corticotomy was not performed as a true osteotomy and the procedure was just only slit in bone, leaving the original bony architecture intact ${ }^{(13)}$.

In group I, there was no significant reduction in GI, while there was significant reduction in GI at 6 months of group II. This clinical improvement that continued during the course of study in GI of group II may be explained by PRF act as a shelter membrane. In addition, its fibrin matrix, cellular and growth factor. It is approved that; good blood supply and safekeeping of the surgical site are essential to improve the soft tissue healing and maturation ${ }^{(14)}$.

The clinical result of our study are in accordance with recent systematic review which concluded that flapless piezocision did not have an adverse impact on the periodontal status, including the PI, $\mathrm{PD}$, attachment levels, gingival recession, mobility scores, and alveolar crest levels or root resorption ${ }^{(15)}$.

Radiographic analysis of group II showed a statistically significant increase of LBT after 6 months. This increase of LBT of the grafted group could be due to the augmentation produced by xenograft and the RAP which is seen in similar kind of injuries. This study in accordance with the findings of study demonstrated that orthodontic treatment with augmented corticotomy enhance bone support and leading to a permanent increase in width of alveolar process ${ }^{(16)}$.

This could be attributed to lateral augmentation of slits with xenografts which provided a source of oestoconduction. Moreover, stripping of mucoperioestum increased RAP in labial plate added to PRF which contained concentrated growth factors such as platelet-derived growth factor, transforming growth factor- $\beta$, and insulin-like growth factor 1 .
This growth factors enriches the blood clot formed and subsequently enhances wound healing and bone regeneration with no inhibitory effect on the natural healing process ${ }^{(17)}$.

The dual use of PRF and xenograft in this study because provided stability for the graft( ${ }^{18)}$. moreover, the presence of a transitory matrix of PRF around the ABB particles facilitates the cellular migration throughout the fibrin network into the regenerative site as well as the development of neoangiogenesis and vascularization, promoting the healing of the site ${ }^{(19)}$. The sponge-like architecture of the biomaterial of PRF provides an ideal scaffold for free cell migration into the surgical site. While the release of growth-factors for up to 28 days post-surgery, provides the continuous long-term stimuli required for chemotaxis and osteogenic differentiation of osteoblasts, PDL cells and bonemarrow mesenchymal stem cells ${ }^{(20)}$.

\section{CONCLUSION}

Uses of guided bone regeneration during cortioctomy improve the clinical parameter and augment the labial bone with minimal loss of bone thickness during en-mass movement.

\section{REFERENCES}

1. Amit G, Jps K, Pankaj B, Suchinder S and Parul B. Periodontally accelerated osteogenic orthodontics (PAOO) - a review. J Clin Exp Dent. 2012; 4:292-6.

2. Hoogeveen EJ, Jansma J and Ren Y. Surgically facilitated orthodontic treatment: A systematic review. Am J Orthod Dentofacial Orthop. 2014; 145: 51-64.

3. Frost HM. The regional acceleratory phenomenon: a review. Henry Ford Hospital Medical Journal. 1983; 31: 1-3.

4. Nimeri G, Kau CH, Abou-Kheir, NS and Corona, R. Acceleration of tooth movement during orthodontic treatment-a frontier in Orthodontics. Progress in orthodontics. 2013; 14: 42.

5. Wilcko WM, Wilcko T, Bouquot JE, and Ferguson DJ.: Rapid orthodontics with alveolar reshaping: two case reports of decrowding. In J of perios \& resto. 2001; 21: 9-19. 
6. Hassan AH, Al-fraidi AA and Al-saeed SH. Corticotomyassisted orthodontic Treatment: review. Open Dent J. 2010; 13: 159-64.

7. Dibart S, Sebaoun JD and Surmenian J. Piezocision: a minimally invasive, periodontally accelerated orthodontic tooth movement procedure. Compend Contin Educ Dent. 2009; 30: 342-4.

8. Cassetta M and Ivani M. The accuracy of computer-guided piezocision: a prospective clinical pilot study. Int J Oral Maxillofac Surg. 2017; 46: 756-65.

9. Wise GE, King GJ: Mechanisms of tooth eruption and orthodontic tooth movement. J Dent Res. 2008; 87: 414-34.

10. Atik E, Coskuner HG, Guven BA and Taner T. Evaluation of changes in the maxillary alveolar bone after incisor intrusion. Korean J Orthod 2018; 48: 367-76.

11. Charavet C, Lecloux G, Bruwier A, Rompen E, Maes N, Limme M, Lambert F: Localized piezoelectric alveolar decortication for orthodontic treatment in adults: a randomized controlled trial. J Dent Res. 2016; 95:1003-9.

12. Yilmaz S, Kuru B, Noyanu U, Argun D, and Kadir T: Effect of gallium arsenide diode laser on human periodontal disease. a microbiological and clinical study. Laser Sug Med 2002; 30: 60 - 6

13. He L, Lin Y, Hu X, Zhang Y, Wu HA: comparative study of platelet-rich fibrin (PRF) and platelet-rich plasma (PRP) on the effect of proliferation and differentiation of rat osteoblasts in vitro. Oral Surg Oral Med Oral Pathol Oral Radiol Endod. 2009; 108: 13. 5.

14. Tonino T, Barbara I, Federica I and Leonardo I.
The Effects of the Combined Use of Platelet-Rich Plasma and Xenograft on Alveolar Socket Healing. Biomed J Sci \& Tech Res. 2018; 3: 1-9.

15. Viwattanatipa N, Charnchairerk S: The effectiveness of corticotomy and piezocision on canine retraction: A systematic review Korean J Orthod. 2018; 48: 200-11.

16. Bhattacharya P, Bhattacharya HA, Bhandari R, Agarwal DK and Gupta A, et al. Assessment of corticotomy facilitated tooth movement and changes in alveolar bone thickness - A CT scan study. J. Clin. Diagn. Res.2014; 8: 26-30.

17. Ehrenfest DM, Bielecki T, Jimbo R, Barbé G, Del Corso $\mathrm{M}$, Inchingolo F, et al: Do the fibrin architecture and leukocyte content influence the growth factor release of platelet concentrates? An evidence-based answer comparing a pure platelet-rich plasma (P-PRP) gel and a leukocyte- and platelet-rich fibrin (L-PRF) Curr Pharm Biotechnol. 2012; 13:1145-52.

18. Ono T, Okamoto K, Nakashima T, Nitta T, Hori S, et al: IL-17- producing $\gamma \delta \mathrm{T}$ cellsenhance bone regeneration. Nature Communications.2016; 7: 109-28.

19. Ghanaati S, Booms P, Orlowska A, Kubesch A, Lorenz J, Rutkowski J, et al: Advanced Platelet-Rich Fibrin (A-PRF) - A new concept for cell-based tissue engineering by means of inflammatory cells. J Oral Implantol. 2014; 40:679-89.

20. Corso DM, Vervelle A, Simonpieri A, Jimbo R, Inchingolo F, Sammartino G, et al: Current knowledge and perspectives for the use of platelet-rich plasma (PRP) and platelet-rich fibrin (PRF) in oral and maxillofacial surgery part 1: Periodontal and dentoalveolar surgery. Curr Pharm Biotechnol. 2012;13:1207-30 